still demonstrable after nine days, they were only present in small numbers. Much less vitality is exhibited by the micrococcus of erysipelas when introduced into waters of various kinds, for even in sewage this organism was not demonstrable on the fifth day. In fact, all the pathogenic micrococci which have been experimented with in this"manner exhibit but little vitality under similar circumstances.

From these experiments it appears, therefore, that whilst ordinary drinking-water does not form a suitable medium for the extensive growth and multiplication of those pathogenic forms which have hitherto been made the subject of investigation in this respect, yet, that in the condition of spores, they are extremely permanent in any lind of water, however pure, and that even those of which no spores are known may often be preserved for days or even weeks.

Thus the investigations which have hitherto been made on the micro-organisms both of air and water, by the light which they throw on the behaviour of micro organisms in general in these media, the manner in which they may be preserved and the manner in which they may be removed, are of great service in indicating how the spread of zymotic diseases through these media is to be avoided.

Until we are fully acquainted with all pathogenic forms of microbes, a consummation which is certainly not likely to be attained in the near future, it is obvious that in endeavouring to exclude dangerous organisms we must attempt to exclude all organisms, e.g. in the purification of water which has been exposed to possibly noxious pollution, that process of purification which insures the removal or destruction of the greatest proportion of micro-organisms must be regarded as the most efficient. In just the same way as in the antiseptic treatment of wounds, the preventive measures employed by surgeons are of such a nature as to destroy or preclude the possibility of growth of any microbes whatever, and not only of those known to be capable of causing mischief.

Percy F, Frankland.

\section{THE OPENING OF THE MARINE BIOLOGICAL LABORATORY AT PLYMOUTH.}

THE Laboratory erected at Plymouth by the Marine Biological Association of the United Kingdom, of which a full account was given last week in NATURE, was opened on Saturday, June 30 . The weather was fine, and at ten o'clock a large and distinguished company were present. Having viewed the tanks, the company assembled in the Laboratory, where Prof. W. H. Flower, C.B., F.R.S., Director of the Natural History Department of the British Museum, delivered an address, in the course of which he said :- "The necessity for such institutions as this has been felt almost simultaneously throughout the cultivated nations of the world. The British Isles, with their extensive and varied seaboard, offering marvellous facilities for the investigation of marine life, with their vast economical interests in the denizens of the waters that lave their shores, have been rather behind some other countries in adopting this line of research. Let us hope, however, that being so, we may profit by example and the experience of others, and ultimately, as in so many other similar cases, may outstrip our neighbours in a department of work for which our maritime and insular position seems so specially to fit us. That our country should be alone in neglecting this branch of scientific inquiry was impossible. Stations for the investigation of the phenomena of marine life have been founded at several places on the northern coasts of our island, but all on a very limited scale. An institution commensurate with the importance of the subject and of the nation had to be established sooner or later; the only questions to be solved were when it was to be founded and where it was to be placed. Much of the success of an enterprise must depend upon the particular time selected for embarking upon it. If delayed too long, the world is a loser by the non-existence of the knowledge that is to be gained from it. On the other hand, premature attempts before sufficient interest in the subject is awakened, or before sufficient information as to the best means of carrying it out has been gained, often end in failure. I think that in this respect we have taken the right medium." After a reference to the Fisheries Exhibition, Prof. Flower continued: - "The question as to the place at which our head-quarters were to be established was at first one of considerable difficulty. Many were the rival claimants, but Plymouth was finally chosen as best approaching the requisite physical and geographical surroundings for such an institution; and the cordiality with which the Association was welcomed by its leading citizens was in itself a ground of justification for the choice. Though a portion of the old military defences of the town has been given tip to our peaceful enterprise, we trust the safety of the inhabitants will not suffer. The Laboratory now stands beneath the Plymouth Citadel and the sea, and an enemy entering the town by the most direct route would have to march over the ruins of the building. That consideration alone should be enough to secure your safety in a war with many of the enlightened science-loving nations of Europe, should such an event unhappily arise. As to the institution itself, few words are needed to show how excellent is its adaptation to the purpose for which it is founded. Although still not in all respects. in full working order, we have been all enabled to see to-day how carefully it has been planned, and how well the design has been carried out. We have secured a capable and energetic working staff, students are already taking their places at our laboratory tables, and already a commencement has been made in their original investigations and contributions to knowledge, which we hope will be of such a character and of such abundance as to give this Laboratory a high place among the scientific institutions of the world. Our present financial position and our future needs are fully set forth in the report of the Council, just issued. This shows that of our capital already subscribed the greater part has been expended on the building and the necessary apparatus for its equipment. We still want a steam-vessel for the use of the staff in exploring the fishing grounds of the neighbourbood and for collecting materials to stock our tanks; and for the means of providing this, and for the annual maintenance of our establishment in a state of efficiency, we shall require further pecuniary assistance. But as the rep ort is, or shortly will be in your hands, I need not detain you longer by enlarging upon its contents. I will therefore, in the name of the President and Council of the Marine Biological Association of the United Kingdom, thank all those who have, by their generous contribution of money or by expenditure of their time, labour, and thought, brought us so far on our way, and declare the Laboratory of the Association open for work. May we all join in the earnest hope that the expectations which have been raised of its future usefulness may never be disappointed."

The company, after being photographed, adjourned to the Grand Hotel on the Hoe, where they sat down to a díjeitiner given by the Fishmongers' Company. Sir James Lawrence, Prime Warden of the Fishmongers' Company, presided, and was supported by the Earl of Morley, Prof. Flower, Sir H. W. Acland, K.C.B., F.R.S, the Mayor of Plymouth (Mr. H. J. Waring), the Mayor of Devonport (Mr. J. W. W. Ryder), the Chairman of the Stonehouse Local Board (Mr. E. A. Lyons), Prof. E. Ray Lankester, LL.D., F.R.S., Sir Edwin Saunders, Sir George Paget, K.C.B., F.R.S., the Ven. Archdeacon Wilkinson, Prof. A. Milnes Marshall, F.R.S., Prof. Charles Stewart, Mr. J. Evans, P.S.A., F.R.S., Captain Wharton, R.N., F.R.S., the Vice-Chancellor of Cambridge, Sir Edward Watkin, M.P., Prof. J. W. Groves, Rear-Admiral H. D. Grant, C.B., MajorGeneral T. C. Lyons, C.B., Mr. Thiselton Dyer, C.M.G., F.R.S., Mr. A. Sedgwick, F.R.S., Mr. W. Pengelly, F.R.S. Mr. F. Crisp, F.R.S., Colonel Hewet, R.E., Rev. J. Hall Parlby, Dr. A. Giinther, F.R.S., Major-General Barton, R.E. Captain Inskep, R. M., Mr. Robert Bayly, Prof. F. Jeffery Bell, Prof. D'Arcy 'Thompson, Prof. G. B. Howes, Mr. C. Spence Bate, F.R.S., Prof. M. Foster, Mr. W. Lant Carpenter, Mr. E. W. N. Holdsworth, Mr. E. L. Beckwith, Fishmongers' Company, Mr. Gilbert C. Bourne, and Mr. J. Solly Foster and Mr. John Hall, Wardens, Fishmongers' Company.

The health of "The Queen" having been given by the Chairman, Lord Morley proposed "The Marine Biological Association of the United Kingdom." He said he was sure that his friends the Mayors of Plymouth and Devonport would join with him in wishing a hearty welcome to the Association, and in sincerely hoping that the Laboratory would prove a success. Any doubt as to the practical value of the Laboratory was dissipated by the fact that the Chairman was one of its main founders, and also that many well-known gentlemen, including the Chairman of the National Association at Kensington and Kew, anticipated good results therefrom. Since there was such a consensus of opinion as to the importance of the scheme from a practical and scientific point of view, the thing which surprised him was why. it was not done before. We reaped the richest harvest from the sea, and yet we had never inquired scientifically into the source 
of this great indust:y. We had lagged behind other nations in this respect. France had no less than four institutions of a similar kind; Austria, with its small coast, had one at Trieste ; and the German Government endowed their Laboratory at Naples, which was the most complete in existence, with $\oint_{15} 50$ a year. From certain statistics recently given to Parliament by the Board of Trade, they learned that the production of fish in the United Kingdom of Great. Britain and Ireland last year amounted in value to six and a quarter millions, and if they took the retail value and not the wholesale value, as put in the statistics, it would amount to not less than thirteen millions per year. The east coast was by far the most fruitful of all our coasts as regards the fishing industry, Grimsby, Hull, Lowestoft, and Yarmouth producing $£_{2}, 800$, 000 worth of fish. Plymouth with its $£ 96,000$ worth of fish per year, Brixham with its $£ 56,000$, and Penzance with its $£ 41,000$, gave some idea of what the sea produced in the shape of food. Comparing these figures with other countries, it would be found that Canada did not produce four millions worth of fish, and France even less. Then they ought to consider the immense amount of traffic our fishing industry gave to our railways. From Plymouth alone there were sent on two lines of railway 50,000 tons of fish annually. It seemed to him an extraordinary thing that so many years should have elapsed before scientific methods were adopted for learning the conditions under which fish live. If they read the interesting Reports of the Trawling and Fishing Com mission, they would be surprised at the ignorance of fishermen as to the habits of fish, their modes of existence, their food, and the climatic and other effects which influenced their existence and modes of living, and he was afraid that ignorance was not confined to fishermen. The great want was, he hoped, about to be supplied in the establishment of this Laboratory. In heartily wishing success to the Marine Biological Association of the United Kingdom, he had the greatest possible pleasure in coupling with it the name of Prof. Ray Lankester.

Prof. Ray Lankester said it was with feelings of pride that he rose to return thanks. It was the great Fisheries Exhibition which suggested the movement for the formation of a laboratory where fishery studies could be carried on. The idea they liad in view at that time, or rather the institution existing elsewhere which they wished to copy, was that established by Dr. Dohrn at Naples, with which they were all familiar. The question was, How could such a laboratory be put up on the British coast? And it was to his friend Dr. Günther, of the British Museum, that they owed the suggestion of the formation of an Association. It was to the officers of the Royal Society that they owed the opportunity of starting the Association. A meeting was called in the rooms of that Society, and presided over by the illustrious President of the great scientific institution, which was also the first public body to support the funds of the Association with a large and handsome subscription, and was very largely attended by men of science and gentlemen interested in fisheries, while the late Earl of Dalhousie, one of their most ardent supporters, the Duke of Argyll, and other public men took part in it. The newspaper Press had all along helped them in a most admirable and cheering manner. The Times had been their warmest friend, and he hoped it would continue to be so for years to come. No soone had the first start been made at the meeting in the rooms of the Royal Society and the subscription list put forward than many other big societies came in and individuals throughout the country put down their money, as did also the Universities of Oxford and Cambridge. Subscriptions had been received from purely scientific bodies and individuals to the amount of $£ 3000$, and from various sources a total sum of $£ 16,000$ to $£ 17,000$ had been obtained. The most important item of support given to the Association was the grant from Her Majesty's Government of $£ 5000$ and $£_{500}$ a year. The remaining $£ 10,000$ they owed to the great civic Companies and to munificent individuals, among whom he must not omit to mention with hearty gratitude their friends Mr. John Bayley and Mr. Robert Bayley, of Plymouth. No sooner had the enterprise been set on foot than His Royal Highness the Prince of Wales expressed his desire to become the patron of the institution, and support came in from every side. 'The Inspector-General of Fortifications and the Earl of Morley were instrumental-were, in fact, the actual causes of their receiving the grant of the splendid site on which the building had been erected; and the co-operation and consent of the Town Council of Plymouth, who had certain rights over the area, were cheerfully given. They had now arrived at a definite stage in their work : the building was completed, the laboratory was equipped, the naturalists were on the spot, and they had thus, as he had said, accomplished what he considered to be the first step in the work of the Association. But it was only the first step. Beyond the mere existence of the laboratory build. ing; they had still to justify themselves in the eyes of their sup. porters by the work that was done within it. He thought they might rely upor the staff they had been fortunate enough to obtain. He had the greatest confidence in the work that would be done in the institution, and in the direction which would be given to that work by his friend Mr. Gilbert Bourne, assisted by the experience of his friend Mr. J. 'T. Cunningham, who had come to them fresh from his work in Scotland, and students of all ages. He would mention once more a subject which had been already alluded to. They wanted a yacht of their own --not a pleasure-yacht, but a steam sea-going vessel which could accompany the trawlers on their expeditions, and should be a thoroughly seaworthy boat. He hoped that those who were able to place additional funds at their disposal, and who had been pleased and gratified with the way in which they had expended the money already intrusted to them, would not delay to add to the resources of the Association so as to enable them to purchase this steamer.

The Prime Warden then proposed "Prosperity to Plymouth," and the Mayor of Plymouth replied.

Sir George Paget, K.C.B., proposed the health of the Prime Warden, who responded, and three cheers having been given for the Fishmongers' Company, the guests dispersed.

\section{UNIVERSITY AND EDUCATIONAL INTELLIGENCE.}

CAMBRIDGE. - The following have been placed in the first class in the Natural Sciences Tripos, Part I. (the names are in alphabetical order):-Baily, Joh.; Daniel, Trin.; Falkener, King's ; Hankin, Joh. ; Horton-Smith, Joh. ; Jones, King's R. Langdon-Down, Trin. ; Locke, Joh. ; Long, Caius ; Morrell, Caius ; Newstead, Christ's ; Perkins, Emman. ; Phear, Trin.; Schott, Trin. ; H. Simpson, Joh. ; H. Smith, Trin. ; W. A. L. Smith, Trin. ; Thornton, B.A., Christ's ; Whetham, Trin, ; G. Wilkinson, jun., Emman.

Women.-Class I.-L. Ackroyd, Newnham; D. Alford, Girton; A. G. Earp, Newnham; L. R. Howell, Girton; M. Kennedy, Girton.

The following have been placed in the first class in the Natural Sciences Tripos, Part II. :-Ds. Anderson, Caius (physiology) ; Barber, Christ's (botany); Ds. D'Arcy, Caius (physics) Ds. Francis, King's (human anat. and physiology) ; Fry, King's (botany); Hardy, Caius (zoology); Hutchinson, Christ's (chemistry); E. R. Saunders, Newnham (physiology).

Mr. A. C. Seward, B.A., Scholar of St. John's College, has been elected Harkness Scholar in geology and palæontology.

Mr. W. W. Watts, M.A., has been elected to a Fellowship at Sidney-Sussex College. Mr. Watts graduated in the Natural Sciences Tripos, 1881, and was placed in the first class for proficiency in geology.

At Downing College the following have been elected to minor Scholarships of $£ 50$ each open to the competition of persons not yet in residence: H. Brownsword, for physics, Manchester Grammar School ; C. Swift, for chemistry, University College, Liverpool ; and $\mathrm{H}$. Widdicombe, private tuition, for botany. G. Dodson has been elected Foundation Scholar for Natural Science.

At Christ's College the following undergraduates have been elected to Natural Science Scholarships: A. H. L. Newstead, $£ 60$; C. Krishnau, $£ 50$; R. H. Luce, $£ 30$; H. M. Stewart, $£ 30$

At King's College, R. C. Fry has been elected Natural Science Scholar, and G. L. Rolleston to an Exhibition of $£ 40$, and L. Falkener to $£ 30$.

At Gonville and Caius College, H. B. Brunner, Berkhampstead School, has been elected to an Entrance Scholarship of $£ 50$ for natural science.

The following Natural Science Scholars have been elected at St. John's College : H. Simpson, Hankin, Horton-Smith, Locke, Baily, Blackman, Schmitz. Turpin, B.A., has been elected Hutchinson Student for organic chemistry. 